by events. The rapid rise of commercial exploitation, including the massive Mariculture enterprise in the Caymans, is posing fast, new challenges to the established thinking of those genuinely concerned with turtle survival. Fundamental questions have to be re-examined and settled with regard to the growth of new markets for turtle products (and new products too) in the balance of wild breeding stocks. These problems have already outstripped Dr Rebel's revision. It is hoped that a specialist working group will very soon face up to the whole new 'ball game' in an IUCN-sponsored conference; and then, as a continuation, in a face-to-face confrontation with Mariculture and other profit-orientated concerns.

Finally, this pleasantly printed and arranged book contains a superbly full, annotated 100-page bibliography, complete and much the best yet in this field, valuable to conservationist, student and specialist alike. The book is worth $\$ 10$ for that alone. And it is urgent that many more conservationists wake up to the world turtle problem forthwith. Since I reported the Morges conference of 1969 ('A Turtle Tragedy', Oryx, $X$. 2:112-115) much research and little conservation have ensued. NONE of the action points there listed have been effectively implemented, even on a regional, let alone international, basis.

TOM HARRISSON

The Capture and Care of Wild Animals, edited by E. Young. Human and Rousseau, Cape Town, R7.50 ( $£ 5.50$ including postage).

Despite the somewhat all-embracing title, this work covers a limited field. It is a technical handbook on capture methods and some aspects of the care of some South African mammals, but it is the first book of its type. It is certainly not a beginner's guide to capture, and it amply illustrates that the successful use of drugs depends on a sound knowledge of animal physiology and medicine. Much of the technical information is available elsewhere but has not been collated before in one volume. The quality and accuracy of the content is somewhat variable.

Harthoorn's review of the available drugs and their properties is particularly well presented and comprehensive, and the chapters by him and Pienaar on herbivore capture are as up-to-date as possible. Buys on the dangers of immobilising drugs to the user, and Basson and Hoffmeyr on causes of mortality following capture are also particularly useful. Young's excellent contribution on the special care of the newly captured animal again highlights why this is not a job for amateurs; his chapter on the general care and nutrition of wild animals in captivity underlines the basic approach to the subject, but some of the data given are likely to be confusing. For example, on the same page (138), two different dose-rates for vitamin A are given for cheetah, one almost certainly too low (5000 i.u. per day), and the other so high ( 20 million i.u. per day) that it would also probably produce problems. The reference for the latter is in fact misquoted. Hirst's chapter on transportation is generally sound but it would have been better to suggest that the handler uses a crate which is say one and a quarter times the length, height and width of the particular animal to be transported rather than dogmatically state the dimensions for each species. The heights given for kudu and eland would, for example, be too small for adults with horns. The crates described for cats and illustrated for cheetahs would seem to be most unsuitable, lacking as they do the privacy and darkness which such an animal requires during transit after recent capture.

The book is well indexed and most chapters are supported by a comprehensive bibliography. Despite its shortcomings, it is the most compre- 
hensive summary of capture techniques now employed in Africa and as such will be of considerable use to wildlife biologists and veterinary surgeons in this field.

D. M. JONES

The African Ark, by R. J. Prickett. David \& Charles, £3.25. The Mitchell Beazley Atlas of World Wildlife. Mitchell Beazley, $£ 9.50$.

The first of these two remarkable publications describes a bold enterprise that achieved astonishing success, despite almost insuperable obstacles; the second is a most ambitious project with Dr Gwynne Vevers as Editorin-Chief and Sir Julian Huxley as Consultant Editor.

Two wildlife-viewing sites in the heart of Kenya's Aberdare montane forests were selected for the Ark, developed under difficulties, and a safari lodge built that affords unique opportunities for seeing bongo, rarest of large forest antelopes, the fearsome giant forest-hog and the elusive leopard. There is a comprehensive and graphically illustrated list of the mammals and some of the more interesting birds; the author also describes some of the lodge guests and their reactions. On one occasion the usual placid spectacle became too realistic when the visitors were witnesses of a grisly demonstration of how the spotted hyena will hunt, pull down and then feast on its still living victim.

Well illustrated - there are two particularly beautiful colour shots of bongo by night, and outstanding monochromes of a greater kudu bull and of a cheetah in three postures-most informative, and highly entertaining, it can be thoroughly recommended.

With the world wildlife atlas the general layout is what one would expect. Broadly, it begins with The World before Man, The Evolution of Life, and Zoogeography and Ecology, followed by the salient details of the zoological and botanical wildlife of continents, sub-continents, oceans and island habitats-in all 88 magnificent and most instructive double-spreads in colour. It concludes with Man and Wildlife, and another 11 doublespreads, covering such important subjects as The Impact of Industry, Changing Role of the Zoo, Man the Protector, Endangered Species, and National Parks and Reserves. Of particular benefit is a really splendid index, as well as a comprehensive list of references.

This atlas is not merely concerned with animal and vegetable life; it also emphasises the importance of various relationships, such as the complex relationship of animals, which is further influenced by vegetation, the terrain and climate. Particularly valuable is the profusion of mapsterritorial, physical, distributional and climatic.

For so lucid a reference compendium on the world's wildlife, its modest price is commendable.

C. R. S. PITMAN

\section{Animals and their Colours, by Michael and Patricia Fogden, Peter Lowe, $£ 3.50$.}

The importance of colour in the lives of animals must be obvious to almost anyone, but it needs someone like the authors, a husband and wife team of professional biologists who have made a special study of the subject in the field in several parts of the world, to make us aware of all its implications.

Starting with an explanation of the nature and variety of animal colours, they review the ways in which colour is used by animals in camouflage, disguise, warning coloration and mimicry. They make a clear distinction between Mullerian mimicry, in which both mimicker and model are 